at the calling office and at the originating office, but it was found to be impracticable to provide a suitable routine testing procedure for the terminating office because of the multiplicity of paths that any particular call might follow. It was decided, therefore, to arrange the terminating marker to apply a continuity test for each call to make sure, before it is disconnected, that a circuit is completed to a subscriber line.

Briefly, the method consists in sending grounded 20-cycle current through the central-office contacts, out on one side of the subscriber line, through the station ringer, or signal, and to ground either at the subscriber station or at the central office. The difficulty associated with widely varying circuit capacitances and resistances was overcome by taking advantage of the difference in phase between the current flowing through the office capacitance and that flowing over the subscriber line, which latter is chiefly resistive under extreme conditions. In the extreme case, when the ground capacitance is zero and the circuit is closed, the current that flows is in phase with the applied voltage, whereas when the capacitance from the 20-cycle supply to ground is a maximum and the circuit is open, the current flowing is $90^{\circ}$ out of phase with the applied voltage. An open circuit with high leakage may thus draw more current than a closed circuit with low leakage, but the angular displacements of the currents with respect to the applied voltage are very different. The new test is based upon this fact, and current flowing in the test circuit is determined from the voltage drop across a condenser in series with the subscriber line. The article describes the test circuits and apparatus in detail and indicates the criteria governing the test.

\section{Philosophy in the Philosophical Magazine}

Although physics is regarded as one of the exact sciences, exactitude was not always found in the titles of its journals. For many years Science $A b$ stracts was regarded as an adequate title for the journal now known as Physics Abstracts, and the London, Edinburgh and Dublin Philosophical Magazine and Journal of Science has published many more papers in physics than in philosophy. In the May number of the latter, however, four of the seven papers are mainly philosophical. Prof. E. T. Whittaker gives a stimulating discussion of "Some Disputed Questions in the Philosophy of the Physical Sciences", using well-chosen analogies. Attention is naturally given to the attempts of mathematicians to discover 'facts' without the use of experiment or observation. As mathematical symbols are not used, the paper is suitable also for the general reader. The other three papers deal with the thorny subject of dimensions. In a brief note, Dr. Norman Campbell points out that writers on the subject are apt to ignore much of the vast literature because "anyone who attempted to summarize the literature would become involved in so many controversies that he could get no further". Since assignment of dimensions is a means to an end, and not an end in itself, writers are urged to state explicitly what end they have in view and how that end is served by the considerations presented in their writings. In a paper of twentyfour pages, Prof. H. Dingle attempts to relate the subject to more fundamental and universally acceptable ideas. Twelve definitions and postulates are given as a set of principles upon which discussion of dimensions may be based. The third paper, by Dr. G. B. Brown, is a reply to some criticisms of Prof. Wilson upon a recent paper on dimensions published originally in the Proceedings of the Physical Society, 53,418 (1941).

\section{Potentialities of the Forests of Latin America}

ProF. S. J. REcond of the School of Forestry, Yale University, raises the question of the utilization of the "enormous areas" of potentially commercial forest in Latin America in a brief article in Tropical Woods (No. 70. Yale University; June, 1942) that deserves wide consideration. He points out the reasons for the lack of demand for tropical lumber. Tropical timbers are different from those growing in the north temperate zone; they may not be inferior but their technical properties are unknown to the consumer. Private commercial concerns naturally do not face the trouble and expense involved in trying out the utility of the new wood for their purpose and they have no guarantee of continuity of supply of the new type. The plain lack is that of subsidized laboratory facilities to make pilot tests on the utility of available timber, to trace defects in supply to their source, to encourage good forestry management and exploitation and to educate the trade in the utilization of the new wood in manufacturing processes. Prof. Record concludes : "Science and Engineering together can find a way to use the tropical forest as a whole and make it a perpetual source, not only of plywood and lumber, but also of unlimited quantities of cellulose, a basic material with a myriad actual and potential applications in industry."

\section{Discovery of the North American Flora}

MANY kinds of trees and shrubs now used in forestry and gardening owe their introduction to the pioneer journeys of David Douglas (1799-1834). These early botanical explorations form the subject of a recent paper by F. R. S. Balfour (J. Roy. Hort. Soc., 67, Parts 4 and 5; April and May, 1942). Douglas's journey to the North Pacific Coast in 1824 was backed by the Royal Horticultural Society, and resulted in the introduction of such garden favourites as Ribes sanguineum and Berberis aquifolium. New conifers were later discovered, namely, Pinus nobilis, $P$. amabilis, $P$. lambestiana, Larix occidentalis, Thuja plicata and many others. Neither shipwreck nor illness deterred this intrepid botanist, and while most of his journeys were made in North America, he met a rather strange death during a journey in Hawaii.

\section{Cancer Control}

AN annotation in the Journal of the American Medical Association of April 18 states that since a cancer control programme was inaugurated fifteen years ago in Massachusetts, about 14,000 patients with cancer, 40 per cent of whom are still alive, have attended the special clinics for the disease. 80.8 per cent of the patients were referred by medical practitioners to the clinics as compared with only $20 \cdot 1$ per cent in the first year of the programme. Between 1927 and 1935, 421 medical men used the tumour diagnostic service as compared with 798 in 1940 . As regards the education of the public, the delay between the time of the first recognized symptom of the disease and the time that the patient obtained 
medical advice averaged $6 \cdot 5$ months in the early years of the programme, whereas between 1936 and 1939 it was $5 \cdot 3$ months and in $19404 \cdot 6$ months. In $1932,31 \cdot 1$ per cent of the fatal cases had never been treated in a cancer hospital, while in 1940 this figure was reduced to $15 \cdot 6$ per cent, indicating that hospitalization for cancer is increasing far more rapidly than cases of the disease.

\section{Biology in Brazil}

WE welcome the appearance of No. 1 (March, 1942) of Vol. 2 of the Revista Brasileira de Biologia, the official organ of the Biological Society of Brazil. The issue runs to 133 pages and contains seventeen papers covering a very wide field of biological subjects including medicine and parasitology. Thus, P. W. Wygodzinsky describes new species of insects of the orders Diplura and Thysanura from Palestine : J. R. Valle and P. R. Souza discuss observations concerning the endocrine system of eighty-four ovoviviparous snakes, and especially the corpora lutea; and F. Feigl and H. Cardoso write on tests for the identification of ascorbic acid. Each volume of the journal is to contain about five hundred pages, comprised in four parts issued in March, June, September and December. The subscription outside Brazil is 4 U.S. dollars, which should be sent to the Secretario da Comissâo de Redaçâo, Mario Vianna Dias, Caixa postal 1.587, Rio de Janeiro, D.F., Brazil.

\section{Health of Ceylon}

According to the report of the Director of Medical and Sanitary Services, Ceylon, in 1940, malaria, as in previous years, was the most prevalent disease in the island, about 97,000 cases having been treated in hospitals and 2,994,000 in dispensaries. The chief outbreak occurred in the south-west early in May and continued until the middle of July. In the northwestern province an epidemic of dysentery, due to the Shiga bacillus, also started in May. During the year the leprosy survey which was begun in 1933 was completed. The total number of patients was 2,771 $-2,032$ males and 739 females-of whom more than a thousand were segregated in two leper asylums. The whole population of Ceylon is estimated at 5,951,000, The total births in 1940 numbered 212,982 , a rate of 35.8 per 1,000 ; deaths amounted to 122,738 , a rate of $20 \cdot 6$. The infant mortality-rate was 149 per 1,000 and the maternal rate $16 \cdot 1$.

\section{Aphids}

A shorT paper by G. Fox-Wilson ( $J$. Roy. Hort. Soc., 67, Pt. 6 ; June, 1942) reviews the horticultural significance and control of aphids. Eradication of these pests is often difficult, and one of the reasons is discussed in the paper. Viviparous stem mothers, when subjected to certain contact insecticides, often remain in a comatose state before death actually occurs, but living nymphs are often produced in this condition. Spraying with nicotine is the best control, but Derris and Pyrethrum washes should be employed where the plant parts attacked are to be used for food.

\section{Physics Bibliography}

THE vital importance of the library as a part of the equipment of a research laboratory is implicitly acknowledged in the Review of Scientific Instruments by the attention given to the current literature of physics in each number of the journal. Twice a year special book numbers are issued, and the spring book number (13, No. 4, April, 1942) contains twentyfour pages devoted to reviews of thirty-eight books on physics. In addition, a two-page "Condensed Library Guide for the Physicist" gives a summary of the standard sources of reference. Copies of the list for the use of students can be bought in quantity from the American Institute of Physics, 175 Fifth Avenue, New York. The list serves as a reminder of the extent to which physics lags behind chemistry in bibliography. The usual monthly survey, "Current Literature of Physics", deals with the research journals. The latest reference to an English journal appears to be that to the issue of NATURE dated February 7.

\section{Announcements}

Is pursuance of the decision of the Secretary of State for the Colonies to open the administrative service in the Gold Coast to Africans, Mr. K. A. Busia and Mr. A. L. Adu have been selected as assistant district commissioners in the Gold Coast. Mr. Busia, an Ashanti, was born in 1913. He was educated in the Gold Coast, where he graduated in 1939, and at University College, Oxford, where he obtained a B.A. degree. Mr. Adu, a member of the Twi tribe, was born in 1914. He attended schools in the Gold Coast, and afterwards went to Queens' College, Cambridge, where he took a degree in natural science.

THE following have been elected to fill vacancies which will occur on the Council of the Institution of Electrical Engineers on September 30 next : President, Prof. C. L. Fortescue; Vice-President, Mr. P. Good; Hon. Treasurer, Mr. E. Leete; Ordinary Members of Council, Prof. J. D. Cockeroft, Mr. A. J. Gill, Mr. D. B. Hoseason, Dr. A. H. Railing, Mr. E. A. Reynolds, Mr. H. W. H. Richards, Mr. J. M. Fleming and Mr. C. W. Bridgen.

AN extensive list of institutions, societies and research workers in the pure and applied plant sciences in Central and South America has been prepared by the editors of Chronica Botanica, in co-operation with the Division of Agriculture of the Office of the Co-ordinator of Inter-American Affairs, Washington, D.C. The list has been published in Chronica Botanica, 7, No. 2 and 3, March and May, 1942 (Chronica Botanica Co., Waltham, Mass.). There are about two thousand names in the list, which is the first of its kind.

Schuman's, of 20 East 70th Street, New York, have issued a catalogue entitled "Medical Miscellany List E". Attention may be directed to the following items: the "Compendium Artis Medicæ" of Bertucius alias Bertuccio or Bertrutius (1537), the "Libri duodecim" of Alexander of Tralles (1556), the "Opuscula anatomica" of Eustachius (1563-64), the first edition of John Hunter's "Treatise on the Venereal Disease" (1786), Morgagni's "De Sedibus et causis morborum" (1820-23), and various early works on anæsthesia. A section on military medicine contains notice of the following important works : George James Guthrie's "Commentaries on the Surgery of the War in Portugal, Spain, France and the Netherlands" (1862), Woodward's "Report on Epidemic Cholera, and Yellow Fever in the Army of the United States during the year 1867" (1868), George M. Sternberg's "Sanitary Lessons of the SpanishAmerican War" (1899), and Caband's "Chirurgiens et blessés à travers l'histoire" (1918). 